\title{
Acquisition of a Dose Management System with Consideration of Medico-Legal and Economic Aspects
}

\section{Beschaffung eines Dosismanagementsystems unter mediko-legalen und ökonomischen Aspekten}

Authors

Thuy Duong Do ${ }^{\circledR}$, Claudius Melzig² ${ }^{2}$, Hans-Ulrich Kauczor² ${ }^{2}$ Marc-André Weber ${ }^{3}$, Mark Oliver Wielpütz², 4

\section{Affiliations}

1 Department of Clinical Radiology, University of Heidelberg, Germany

2 Department of Diagnostic and Interventional Radiology, University of Heidelberg, Germany

3 Universitätsmedizin Rostock, Diagnostische und Interventionelle Radiologie, Rostock, Germany

4 Translational Lung Research Center TLRC Heidelberg, German Center for Lung Research DZL, Heidelberg, Germany

Key words

dose management system, investment, radiation protection

received 25.05 .2021

accepted 07.11.2021

published online 21.12.2021

Bibliography

Fortschr Röntgenstr 2022; 194: 363-372

DOI 10.1055/a-1710-3529

ISSN 1438-9029

(C) 2021. Thieme. All rights reserved.

Georg Thieme Verlag KG, Rüdigerstraße 14,

70469 Stuttgart, Germany

Correspondence

Thuy Duong Do

Department of Diagnostic and Interventional Radiology,

University of Heidelberg, Im Neuenheimerfeld 420,

69120 Heidelberg, Germany

Tel.: $+49 / 6221 / 566410$

Fax: $+49 / 6221 / 565730$

thuyd_do@gmx.de

\section{ABSTRACT}

Background New radiation protection regulation encompassing additional obligations for monitoring, reporting and recording of radiation exposure, was enacted on December 31,2018 . As a consequence, dose management systems (DMS) are necessary to fulfill the requirements. The process of selection, acquisition and implementation of a suitable IT solution for this purpose is a challenge that all X-ray-applying facilities, including hospitals and private practices, are currently facing.
Method A target/actual-analysis as well as a cost-utility analysis is presented for this specific case as a foundation for the acquisition decision-making process.

Result An actual analysis is necessary in order to record the current status of dose documentation. An interdivisional approach is recommended to include all imaging modalities and devices. An interdisciplinary steering committee can be helpful in enabling consensus and rapid action. A target analysis includes additional criteria with respect to ease of operation, technical feasibility, process optimization and research opportunities to consider in addition to the statutory requirements. By means of a cost-benefit analysis, considerations between costs and the individually weighted advantages and disadvantages of eligible DMS result in a ranking of preference for the available solutions.

Conclusion Requirements of a DMS can be summarized in a specification sheet. Deploying an actual condition analysis, target state analysis and cost-utility analysis can help to identify a suitable DMS to achieve rapid commissioning and highest possible user acceptance while optimizing costs at the same time.

\section{Key Points:}

- An actual analysis reveals optimization and standardization needs in examination protocols and technical coding of dose data that can be addressed before or during the acquisition process.

- A specification sheet covers all functional, technical, and financial aspects of a target analysis.

- A cost-utility analysis is useful for exploring an appropriate dose management system with high user acceptance, rapid implementation, and low cost.

- An interdisciplinary steering committee can be helpful to enable early consensus building and fast action.

\section{Citation Format}

- Do TD, Melzig C, Kauczor H et al. Acquisition of a Dose Management System with Consideration of Medico-Legal and Economic Aspects. Fortschr Röntgenstr 2022; 194: 363-372

\section{ZUSAMMENFASSUNG}

Hintergrund Seit dem 31.12.2018 ist die neue Strahlenschutzverordnung rechtswirksam, die zusätzliche Überwachungs-, Melde- und Aufzeichnungspflichten enthält. Um 
diesen Aufgaben gerecht zu werden, sind Dosismanagementsysteme (DMS) erforderlich. Der Prozess der Auswahl, Anschaffung und Implementierung einer hierfür geeigneten IT-Lösung stellt eine Herausforderung für alle Röntgenstrahlen-applizierenden Einrichtungen, sowohl für Kliniken als auch Arztpraxen, dar.

Methode Es werden IST-/SOLL-Analysen und Kosten-Nutzwert-Analysen für diesen spezifischen Fall dargelegt, um eine fundierte Grundlage für die Entscheidungsfindung bei der Auswahl eines geeigneten DMS zu bilden.

Ergebnis Eine IST-Analyse ist notwendig, um den aktuellen Stand der Dosisdokumentation zu erfassen. Dabei ist ein abteilungsübergreifendes Vorgehen zu empfehlen, um alle Bildmodalitäten und Geräte zu berücksichtigen. Ein interdisziplinärer Lenkungsausschuss kann dabei hilfreich sein, um eine frühzeitige Konsensfindung und schnelles Handeln zu ermög- lichen. Die SOLL-Analyse umfasst neben den gesetzlich vorgeschriebenen Anforderungen zusätzliche Kriterien hinsichtlich der Anwenderfreundlichkeit, technischen Umsetzbarkeit, Prozessoptimierung und Forschungsmöglichkeiten zu berücksichtigen. Eine Kosten-Nutzwert-Analyse ermöglicht schließlich durch die Abwägung zwischen den Kosten und den individuell gewichteten Vor- und Nachteilen der unterschiedlichen DMS eine Rangfolge der Präferenz für die infrage kommenden Lösungen zu erstellen.

Schlussfolgerung Anforderungen an das DMS können in einem Lastenheft zusammengefasst werden. Mithilfe von IST-Analysen, SOLL-Analysen und Kosten-Nutzwert-Analyse kann das geeignete Produkt sondiert werden, um eine schnelle Inbetriebnahme und eine möglichst hohe Nutzerakzeptanz bei gleichzeitig optimierten Kosten zu erreichen.

\section{Background}

In 2013, new guidelines for radiation protection were issued by the European Atomic Energy Community under the name EURATOM 2013/59 [1]. These guidelines served as the basis for the amended German Radiation Protection Act (StrlSchG), which was enacted on May 12, 2017. The supplementary Radiation Protection Ordinance (StrlSchV) has been legally effective since December 31, 2018 [2]. The new ordinance now contains extended monitoring, reporting and recording obligations [3]. According to paragraph 122 of the Radiation Protection Ordinance, the exposures of persons receiving ionizing radiation shall be regularly evaluated and assessed. In addition, the new ordinance requires the use of specialized personnel in radiation protection, so-called medical physics experts (MPE). Although the acquisition of a dose management system (DMS) as a technical solution is not explicitly mentioned in the draft law, nevertheless, the use of such an automated IT solution is practically mandatory in order to fulfill the new legal requirements and tasks of the newly introduced MPE. Appropriate software can support clinics and practices in the implementation of the legal requirements for radiation protection. The first dose management systems were developed in the early $2000 \mathrm{~s}$, and most current systems in their current form have been approved for the market in the last 5-10 years. Diagnostic reference values have only been compiled by the Federal Office for Radiation Protection in Germany since 2003 and are used for comparison with the applied dose in the specific institute or practice in order to better classify internal values and to recognize the potential for optimization.

\section{Methods}

The following presents the analysis and preparation of the selection process for a DMS software and related cost-utility analysis. In contrast to a cost-benefit analysis, the cost-utility analysis takes into account both monetary and non-monetary criteria which are assessed with weighting factors. Thus a cost-utility analysis assesses the effectiveness rather than the efficiency of an approach. This is intended to enable a rapid exploration of suitable software and its implementation, as well as to obtain the maximum benefit for the user.

\section{Actual analysis of dose documentation}

Actual analysis is indispensable, because only with knowledge of this can target analyses be carried out and includes both the inventory of all devices for the application of ionizing radiation to humans, the recording of current dose documentation and identification of all departments that have related devices in operation. The dose management system should not only be a department-specific solution in radiology, but should also be applied across the entire hospital. This dose documentation including MPEs is also mandatory for practices and medical care centers for the commissioning of new devices. For existing equipment, there is a transition period for the MPE until the end of 2022. The disciplines involved include general diagnostic and interventional radiology, pediatric radiology, and neuroradiology as the main users of the DMS. In addition, there are other stakeholders that operate $\mathrm{X}$-ray equipment, for example mobile C-arms, fluoroscopy equipment and angiography equipment, such as cardiology nuclear medicine, radiotherapy, vascular surgery, orthopedics, trauma surgery or gastroenterology (see $>$ Fig. 1). Likewise, the radiation safety officer should be involved in the planning process. Across departments, the person responsible for radiation protection (usually the hospital's chief medical director) should also be informed about the acquisition of a DMS. The administrative management of the hospital should be involved in the project from the beginning to ensure continuous support. Lack of support by administrative managers is among the top ten reasons for the failure of a large IT project [4]. There is the additional possibility to bring in an external consultant to support the process successfully [5].

Dose information varies with the imaging technique and may be encoded in different formats for this purpose: DICOM Radiation-Dose-Structured Report (RDSR), optical character 


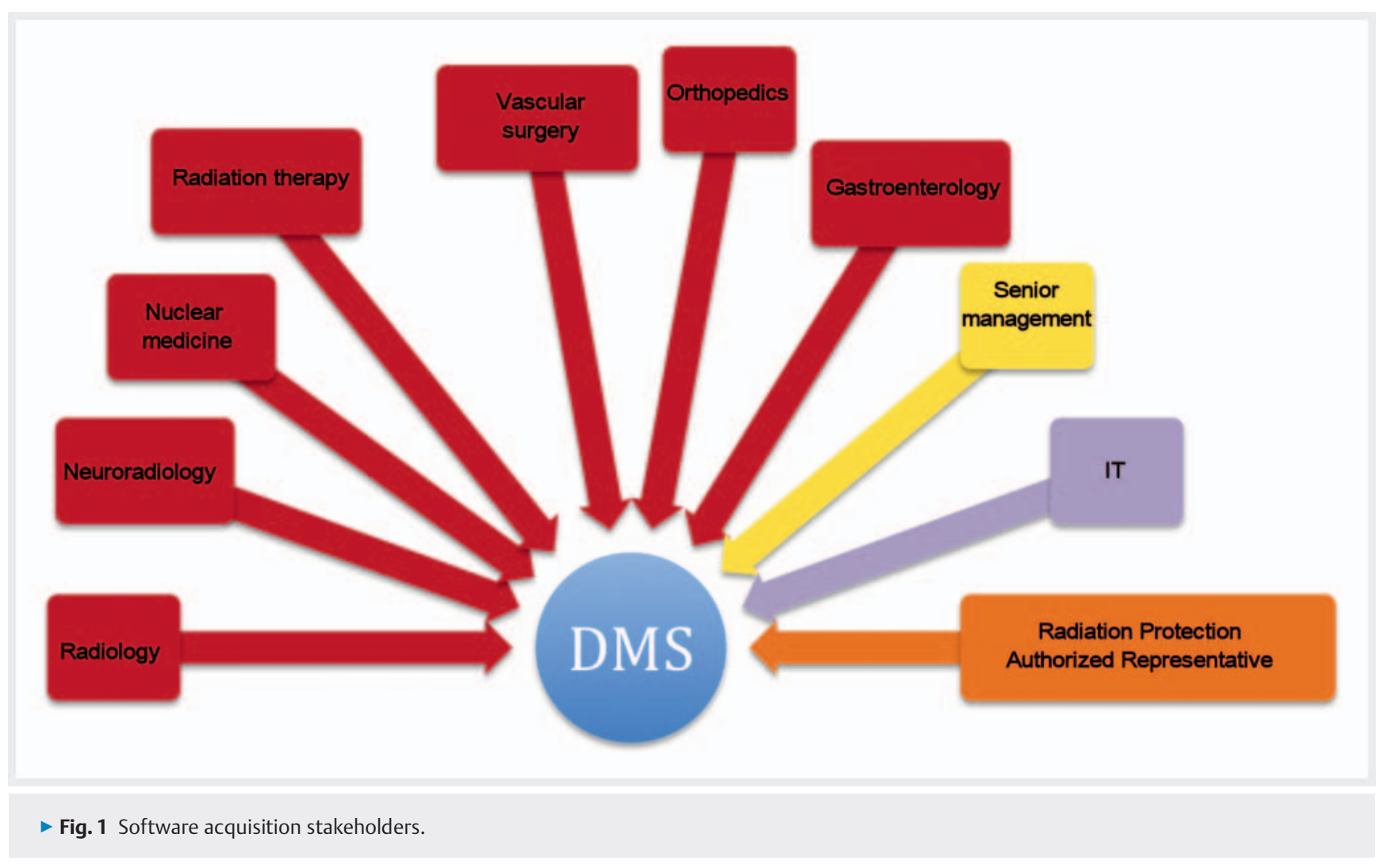

recognition (OCR), DICOM-modality performed procedure steps (MPPS) or in DICOM header data [6]. RDSR was introduced as an international standard in 1993 to facilitate the exchange and comparability of dose information between different manufacturers and centers [7]. It is therefore advisable to switch to uniform coding at the very beginning of the DMS acquisition process.

To simplify the assignment of examination protocols (so-called mapping) to the national dose reference values of the Federal Office for Radiation Protection or additionally internally defined dose reference values, prior to software acquisition it is useful to standardize current processes and investigation protocols within the department and across departments to achieve a systematic approach with correct terminology, classification and comparability. Specifically, this means that all examination protocols for a procedure performed at different sites and departments are also filed with the same name, e. g. "CT thorax native".

\section{Actual analysis}

A meaningful list of requirements analysis for the DMS can be derived and prioritized, taking into account weak points can be developed only with knowledge of the actual analysis of the current dose acquisition including dose parameters, storage format of dose information and internal data linking nodes between acquisition consoles, PACS and software for report generation. Not only functionalities resulting from legal requirements should be considered, but also the overall corporate strategy and IT strategy as well as future multi-client capability, e. g. dose monitoring also for affiliates such as a hospital-owned medical care center. Research focusing on radiation protection should be considered for functions of the DMS that can be additionally acquired. Likewise, possible center certifications can be weighed with radiation protection as a quality feature as part of the acquisition of a DMS, e.g., in the context of EuroSafe imaging certifications [8]. All functional and financial requirements for the DMS can be summarized as a so-called specification sheet and used as a guide for the specific information request to the manufacturer [5].

\section{Legal requirements}

As a minimum requirement, the DMS must fulfill all technical and quality specifications of the new Radiation Protection Act at the federal level as well as the specifications of the respective state medical associations. Equipment and modalities CT, PET $C T$, angiography equipment and X-ray equipment should be linked in order of urgency and potential exposure. This prioritization is based on the legally determined deadlines and related dose intensity and has been jointly decided by the hospital's steering committee composed of representatives of the various departments. Starting January 1, 2021 all newly installed, and from January 1, 2023, existing devices for computed tomography or fluoroscopy must comply with the regulations for dose recording and documentation. This implementation will take effect for X-ray equipment January 1, 2024. Optionally, 


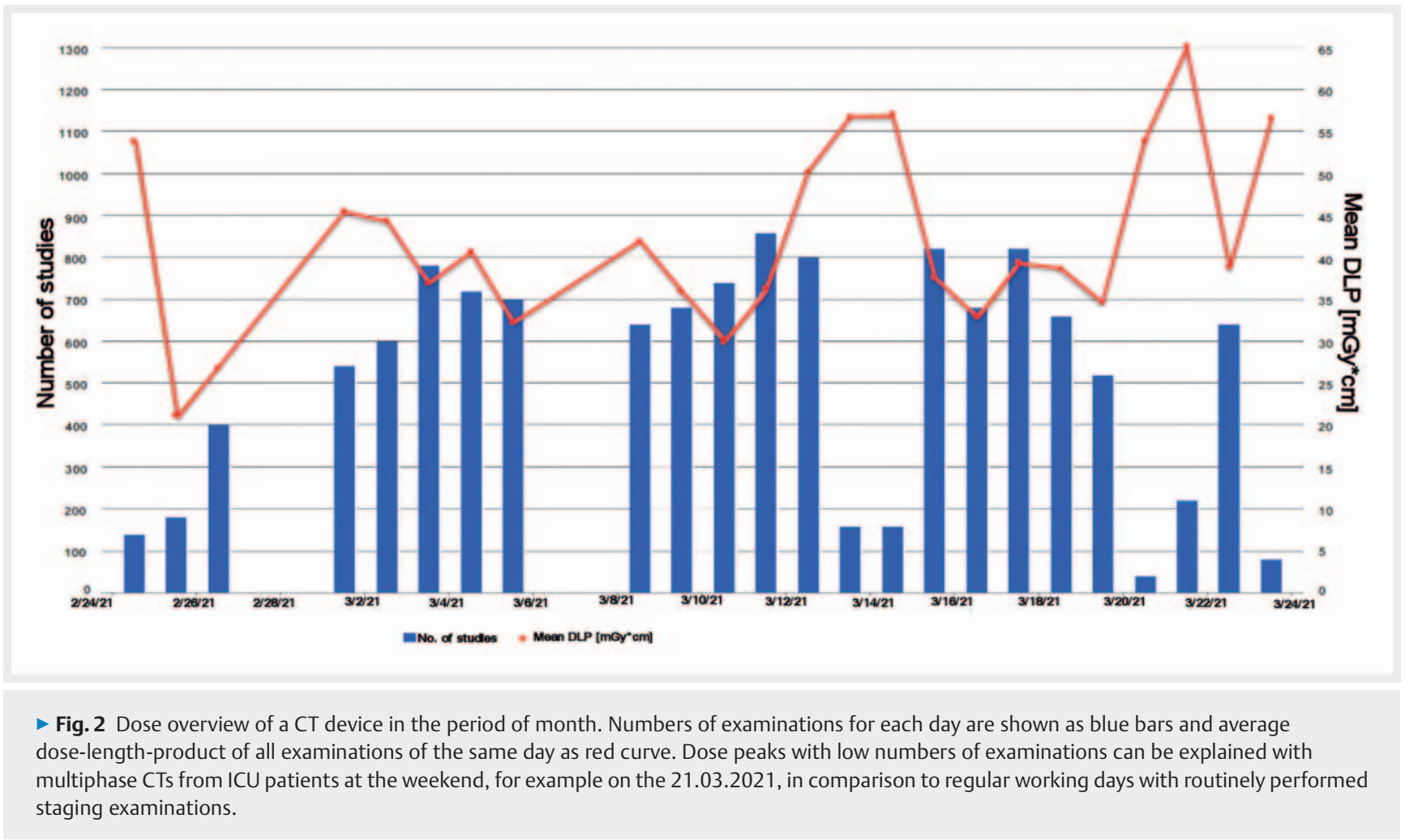

MRI and ultrasound devices of a department can also be connected. Although these equipment types do not operate with ionizing radiation when connected, most vendors provide information for utilization analysis and process optimization.

\section{Key figures and benchmarking}

Results of dose analysis can be presented in the form of ratios and graphs with statistical tools for an easier overview of dose values on a patient-by-patient basis, as well as per action, per device

( $\triangleright$ Fig. 2), or in larger units such as department or overall hospital.

- Deviations from national dose reference values or dose thresholds defined internally by the department.

- Separate analyses by protocol ( $\triangleright$ Fig. 3), modality, location and department.

- Analyses by study classification, patient age and body mass index class.

- Analysis for self-adjustable time periods and times of day ( Fig. 4).

As another quality management option, the comparison of the total dose used per examination per patient with the externally or internally defined dose thresholds should be carried out as part of a benchmarking procedure. The diagnostic reference levels of the Federal Office for Radiation Protection or the “European Study on Clinical Diagnostic Reference Levels EUCLID" of the European Society of Radiology can be used as external dose reference levels $[9,10]$. The former has already been implemented in the DMS of all manufacturers.

\section{Utilization analyses}

\section{Configurability of messages in case of dose exceedance}

The user should be automatically informed when dose thresholds are exceeded and reportable events are detected by the DMS. Manual configuration option of the message frequency (hourly, daily, weekly) should prevent excess interference with the regular workflow. Exceeding the dose reference value alone is not a notification criterion. When the threshold of $300 \%$ of the respective dose reference value is exceeded, an action threshold is reached that requires a review of the average of the last 20 examinations of the same examination type on the same device. Notification is required if the latter is higher than $200 \%$ of the dose reference value.

\section{Contrast agent management}

In addition to the dose, it is also possible to manage contrast agent consumption by accessing information from the contrast medium injectors or the PACS. The contrast media, quantity, type and flow rates used are thus documented and can be compared with the number of examinations. This should facilitate the management of MRI and CT contrast agents, calculation of the optimal delivery quantity and timing to avoid long storage times or delivery bottlenecks. The optimal order quantity or time can be calculated using the Andler formula [11] to minimize storage and ordering costs. 


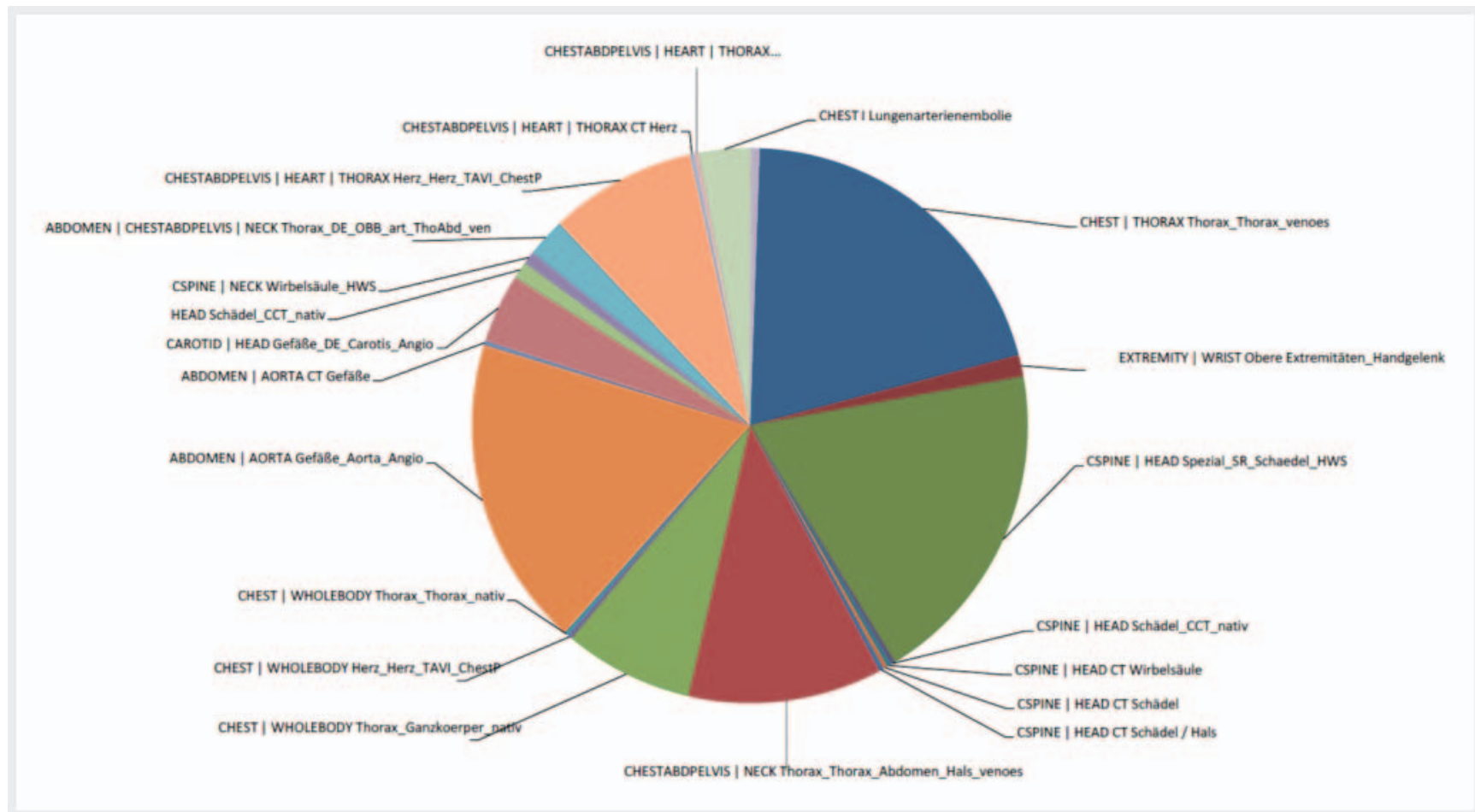

- Fig. 3 Distribution of acquisition protocols on a CT device over a period of one month.

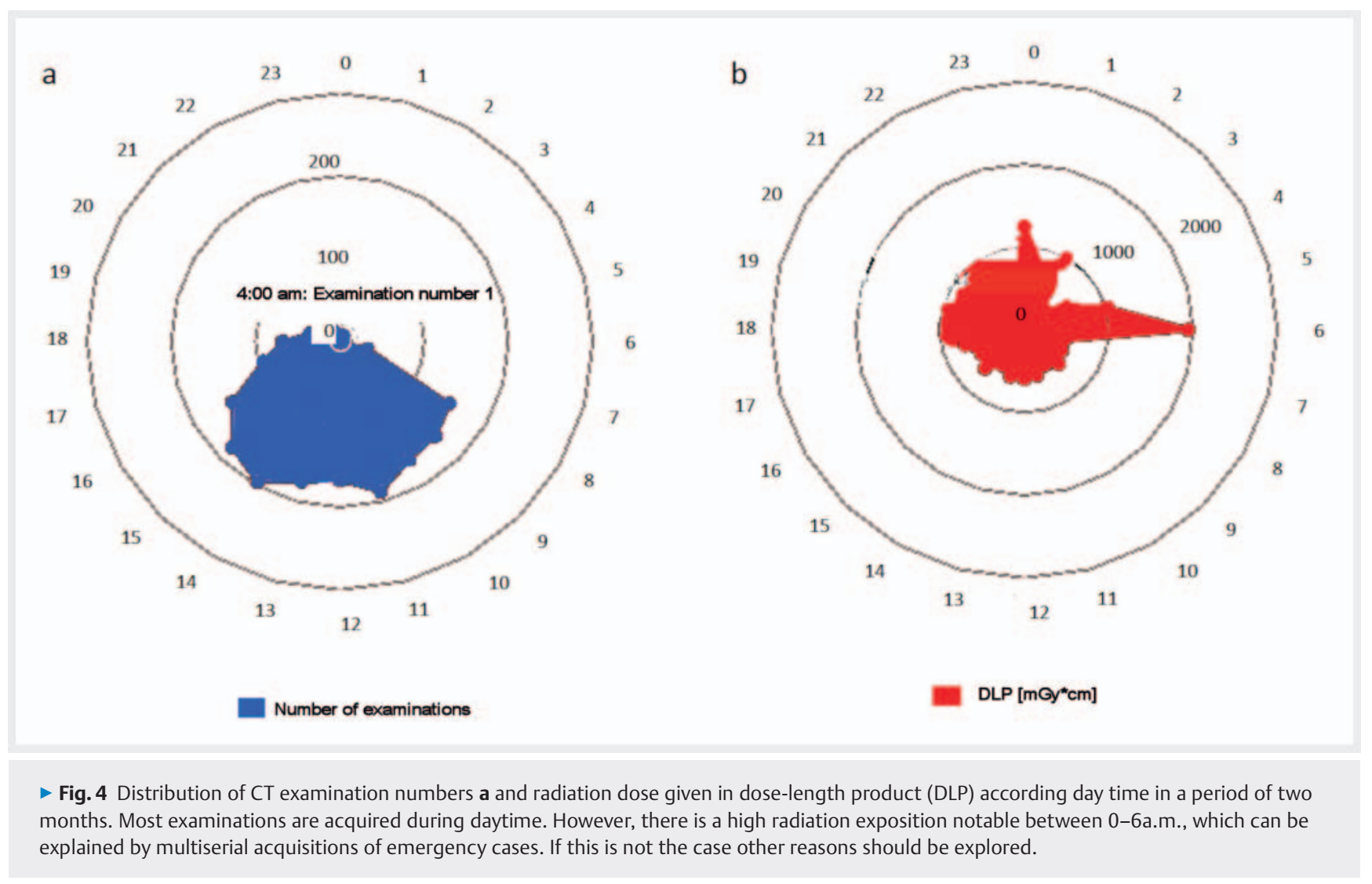




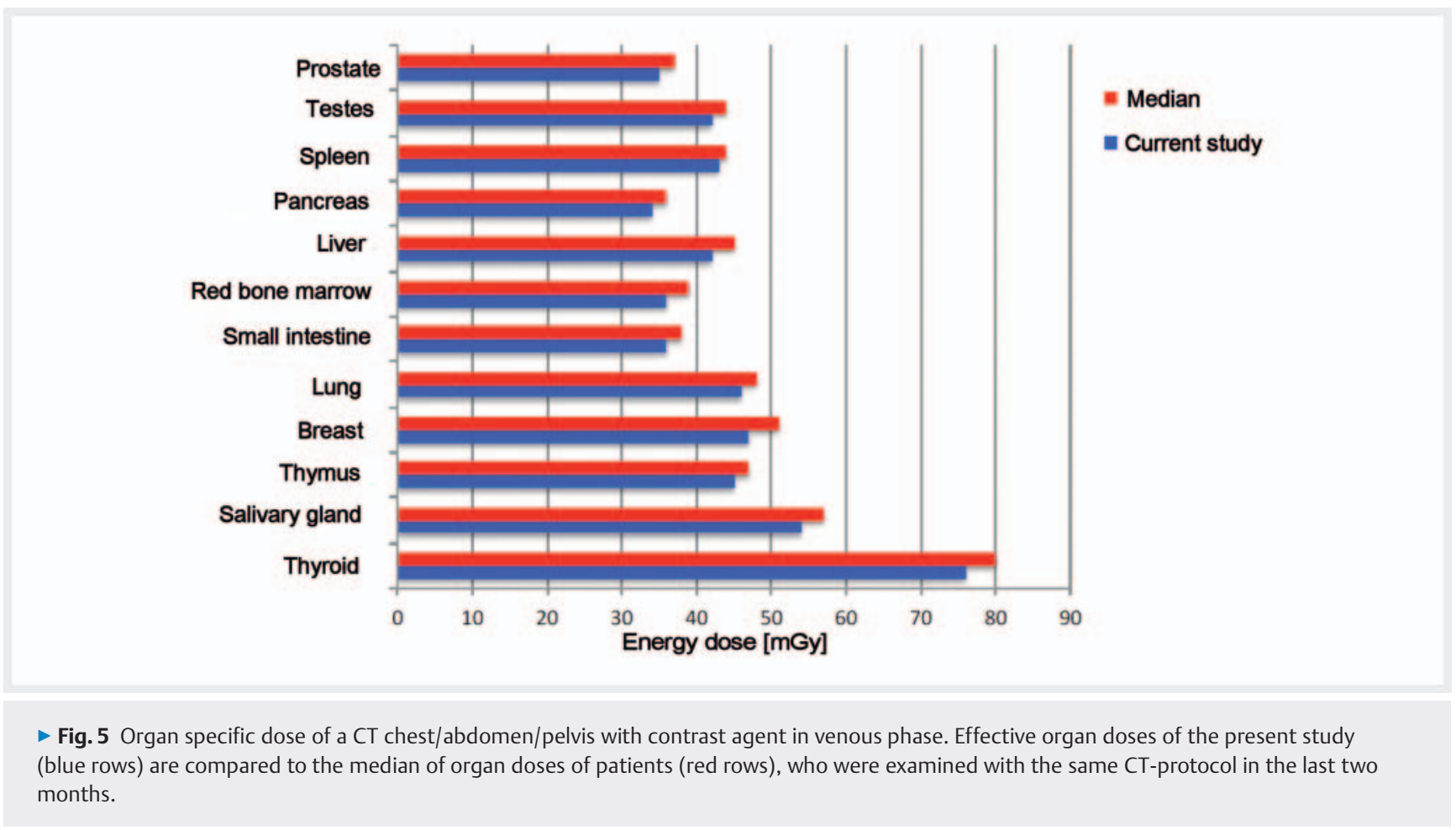

\section{Research options}

"Size-specific dose estimates" (SSDE) give a size-related estimate of the organ dose and take into account the body habitus and the radiation sensitivity of the organs in the calculation [12]. The availability of SSDE and thus better comparability of patient dose despite different physiques yields additional data for research in radiation protection and image quality ( $\bullet$ Fig. $\mathbf{5}$ ). The possibility of data export of dose parameters and related images should be included in the consideration to facilitate scientific evaluations.

\section{Technology and data security}

The new DMS should be technically compatible with the existing equipment of various manufacturers and able to read the dose information. Ideally, the dose information should be generated at the modality in the form of RDSR and transmitted to the DMS, since this is the most complete form to access structured data and compare dose parameters between devices from different equipment manufacturers. Conversion to that format requires additional service calls with the respective equipment manufacturers and generates opportunity costs due to missed examinations, which must be factored in financially and with respect to time. Furthermore, depending on technical availability, it must be ascertained whether a dedicated server or cloud solution should be used as "Software as a Service" (SaaS) $[13,14]$. In the former instance, the server is physically located at the entity's own premises and is accompanied by decentralized data management, which means that the data remains internally at the institution. The rights of use belong to the institution and can presumably more easily meet high security requirements. In addition, analyses can be performed faster and the correlation with patient data is guaranteed. In the second instance, dose data is sent anonymized from the hospital to the software company via the Internet, and the dose report on individual examinations is analyzed and stored in the cloud in each case. Anonymized data, unlike pseudonymized data, is not subject to data protection. The advantages of the cloud solution are that operation and maintenance are carried out by the provider. With a cloud solution, operational responsibility is usually shared and contractually defined. Other possible included advantages are continuous update and improvement of the software on the part of the provider, clear cost structure without the client's internal operating costs and especially no acquisition costs for hardware. A cloud solution together with concomitant centralized data management makes it possible to compare with other centers that also access the same cloud.

\section{Financing}

At the outset it should be ascertained whether the acquisition of a blanket license for the entire institution is possible or whether this should be done as single licenses. Individual licenses can be advantageous if only a few people use the DMS, e. g. a single practice or group practice. In individual cases, a single license can be interesting for large institutions such as the university hospital if only one or a few new devices are being put into operation, if legal requirements have to be met, and to bridge the time before an institution-wide DMS can be installed. Likewise, these costs must be weighed against each other. When calculating the costs, not only the one-off fixed costs at the time of purchase should be negotiated, but also the followup costs arising from updates and maintenance. In addition, 
there should be no restrictions on the connection of additional modalities when purchasing a campus license.

\section{Comparison of the actual and target analyses}

Comparison of the actual analysis with the target analysis reveals weak points in processes and organizational structures that can be eliminated before the DMS is acquired. Standardization of dose protocols and the underlying technical dose coding, preferably the RDSR format, set the course for a future rapid connection to the DMS.

\section{Make or buy decision}

Once the requirements for a DMS are known, the first question that arises is whether the application should be developed by the institution itself or commissioned from an external provider (custom software) or whether it can be purchased as standard software. Currently there are more than 14 standard software solutions for radiation dose evaluation on the market. A customized solution is advantageous over standard software if there is no ready-made solution on the market for the specific requirement or if it provides competitive advantages over other companies. However, in the hospital sector and in practice, the focus is on healthcare, clinical research and basic research than on creating advantage through custom software.

\section{Cost-Utility Analysis}

A cost-utility analysis compares the weighted advantages of a DMS with the costs of acquisition and maintenance [15, 16]. The utility value is the sum of the calculated point values of individual criteria, taking into account a weighting factor. Criteria are sorted by groups and evaluation of group weighting at the same hierarchical level appears to be the most useful [17]. The weighting of the categories can be freely determined by the steering committee, e. g. price $40 \%$, benefit assessment $18 \%$, scope of delivery, period and service $2 \%$ and technical evaluation $40 \%$. An individual adjustment of the numerical values according to local needs should be made. The cost-utility analysis is intended to serve as a decision-making basis for investment considerations of an available DMS. In addition, financing of the acquisition costs should not exceed the institution management's target. Taking into account the utility and cost analysis, it is then possible to apply a ranking with an ordinal scale to determine a preference for a provider [18].

\section{Cost analysis}

A distinction can be made between total costs (fixed costs) for one year's use and follow-up costs ( $\downarrow$ Table $\mathbf{1}$ ). The total cost includes all costs, such as the price of the software, its installation, implementation and training including hardware and software components. The follow-up costs are made up of service costs and license costs, which are incurred by each manufacturer at different times, such as after expiry of the warranty, after written acceptance or connection of additional modalities. Due to legal requirements, such as the necessary
- Table 1 Fixed costs and follow-up costs in a dose management system.

\begin{tabular}{|c|c|}
\hline fixed costs & follow-up costs \\
\hline $\begin{array}{l}\text { - licensing fee } \\
\text { - software and hardware } \\
\text { components } \\
\text { - installation charges by the } \\
\text { software developer and } \\
\text { device manufacturer } \\
\text { - transaction costs } \\
\text { - implementation costs and } \\
\text { overhead due to network } \\
\text { integration } \\
\text { - internet access costs } \\
\text { - software training costs } \\
\text { - costs for work loss due to } \\
\text { individual training }\end{array}$ & $\begin{array}{l}\text { - service costs per year } \\
\text { " system management costs } \\
\text { (physicists, technicians, } \\
\text { physicians) } \\
\text { - post-training costs } \\
\text { - costs due to workflow } \\
\text { disruption } \\
\text { - costs in the event of necessary } \\
\text { process optimizations } \\
\text { (as a result of excess doses) } \\
\text { - hardware-related energy costs } \\
\text { - space costs for it center, if } \\
\text { necessary }\end{array}$ \\
\hline
\end{tabular}

- Table 2 Proposal of a cost calculation.

\section{price list evaluation criteria}

\section{dose management system}

price for software including installation/implementation as well as instruction and training including all required hardware and software components

annual service costs

total costs for year 1 (procurement + service costs, without posttraining/instruction) $+19 \%$ VAT (gross)

follow-up costs year 2 (service costs without post-training/instruction) $+19 \%$ VAT (gross)

follow-up costs year 2 (service costs without post-training/instruction) $+19 \%$ VAT (gross)

total 3 year costs

offer total (net)

$+19 \%$ VAT (gross)

price reduction $\times \%$ discount when payment within agreed period after invoice

offer final price including discount (gross)

vendor points (,ax. 400 points)

vendor price ranking

hiring of MPEs and the acquisition of a DMS, the operating costs for installation, system management by physicians and medicaltechnical radiological assistants (MTRA) are not considered subsequently when selecting software. These are costs that are incurred in a DMS acquisition regardless of the manufacturer. Operating costs for installation, system management by physicians and MTRAs can vary greatly depending on the manufacturer of the DMS. Setup is a line item for labor time for physicians/MTRAs/MPEs which cannot be accurately estimated in advance. A rudimentary evaluation of these can be found in 


\section{Evaluation Matrix}

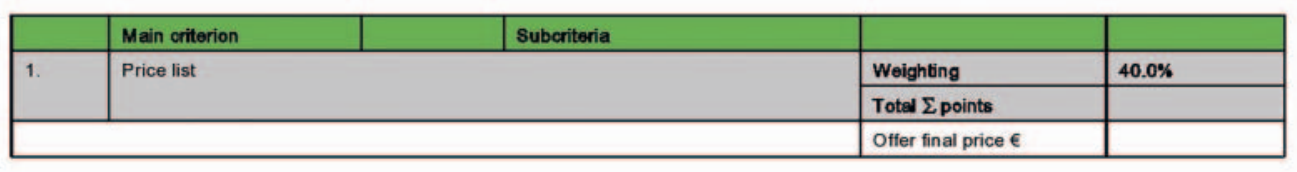

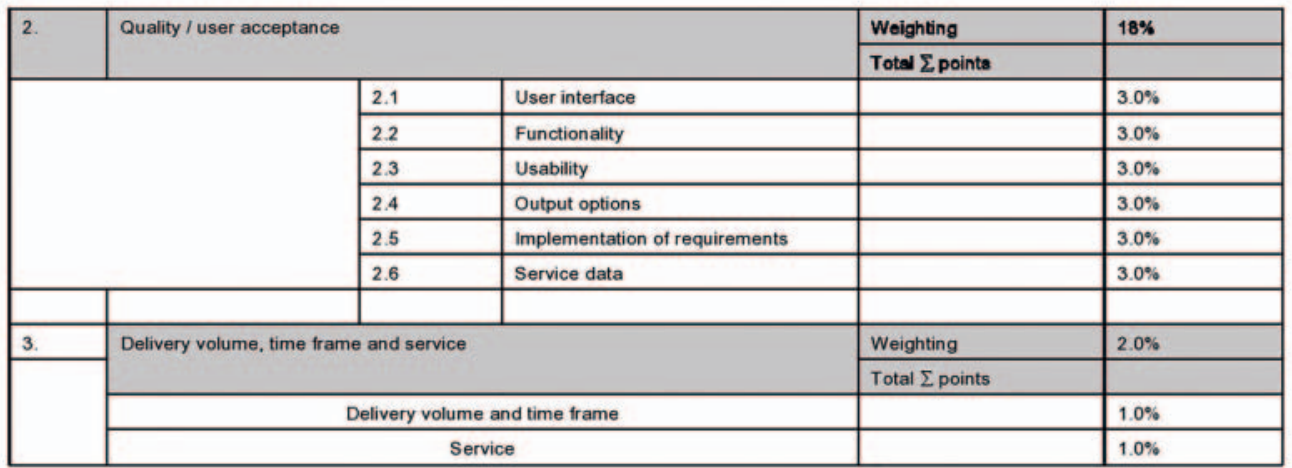

\begin{tabular}{|c|c|c|c|c|c|}
\hline \multirow[t]{2}{*}{4.0} & \multicolumn{3}{|l|}{ Technical evaluation } & \multirow{2}{*}{$\begin{array}{l}\text { Weighting } \\
\text { Total } \Sigma \text { points }\end{array}$} & \multirow{3}{*}{$\begin{array}{l}40 \% \\
32.0 \% \\
\end{array}$} \\
\hline & \multirow{2}{*}{ Software requirements } & \multirow{3}{*}{$\begin{array}{ll}4.1 \\
4.1 .1 \\
\end{array}$} & \multirow[b]{2}{*}{ Overall } & & \\
\hline & & & & Total & \\
\hline & & & Basic requirements & & $0.0 \%$ \\
\hline & & 4.1 .2 & Connection to modalities & & $2.0 \%$ \\
\hline & & 4.1 .3 & Authorization concept & & $1.0 \%$ \\
\hline & & 4.1 .4 & Dose documentation - overall & & $12.5 \%$ \\
\hline & & 4.1 .5 & Dose assessment & & $5.0 \%$ \\
\hline & & 4.1 .6 & Dose assessment - additional options & & $2.5 \%$ \\
\hline & & 4.1 .7 & Alarm notifications & & $2.0 \%$ \\
\hline & & 4.1 .8 & Reporting & & $3.0 \%$ \\
\hline & & 4.1 .9 & Utilization analyses & & $4.0 \%$ \\
\hline & Additional options & 4.2 & Overall & Total & $8.0 \%$ \\
\hline & & 4.2 .1 & Contrast agent management & & $4.0 \%$ \\
\hline & & 4.2 .2 & Data export options & & $2.0 \%$ \\
\hline & & 4.2 .3 & Quality management & & $2.0 \%$ \\
\hline \multicolumn{5}{|c|}{ Percent total } & $100.0 \%$ \\
\hline \multicolumn{5}{|c|}{ Total points } & \\
\hline
\end{tabular}

Vendor ranking

- Fig. 6 Example of an evaluation matrix of all main criteria of a dose management system.

the usability criterion under the heading utility analysis in the context of a product presentation.

In addition, discounts offered by companies are also to be taken into account. A period of 3 years is used to calculate the costs of a DMS, since the amortization period of standard software is 3 years. In the case of custom software, an amortization period of 5 years can be applied.

For example, a point scale from 0 to 400 points, so-called vendor points, is standardized for the assessment of an offer. The higher the number of vendor points for the respective software offer, the more interesting the offer is for the institution. A notional maximum price limit is set at twice the value of the lowest offer. Only offers that fall between the lower and upper price limits should be considered. All offers above this notional price limit are awarded 0 points, as the price limit criterion is not met. A point evaluation with linear interpolation is carried out as follows [19]:

vendor points $=400-\left[\left(\frac{\text { offer } \text { price }- \text { price }_{\text {Min }}}{\text { price }_{\text {Min }}}\right) \times 400\right]$

- Table 2 provides an overview of a possible cost calculation.

\section{Utility analysis}

For the utility analysis, suitable market suppliers can be sorted out on the basis of the specifications and invited for a product presentation. Members of the steering committee can perform a qualitative assessment of the utility by using a 10-point scale. Important quality criteria include the evaluation of the user interface, functionality, usability, implementation of legal 


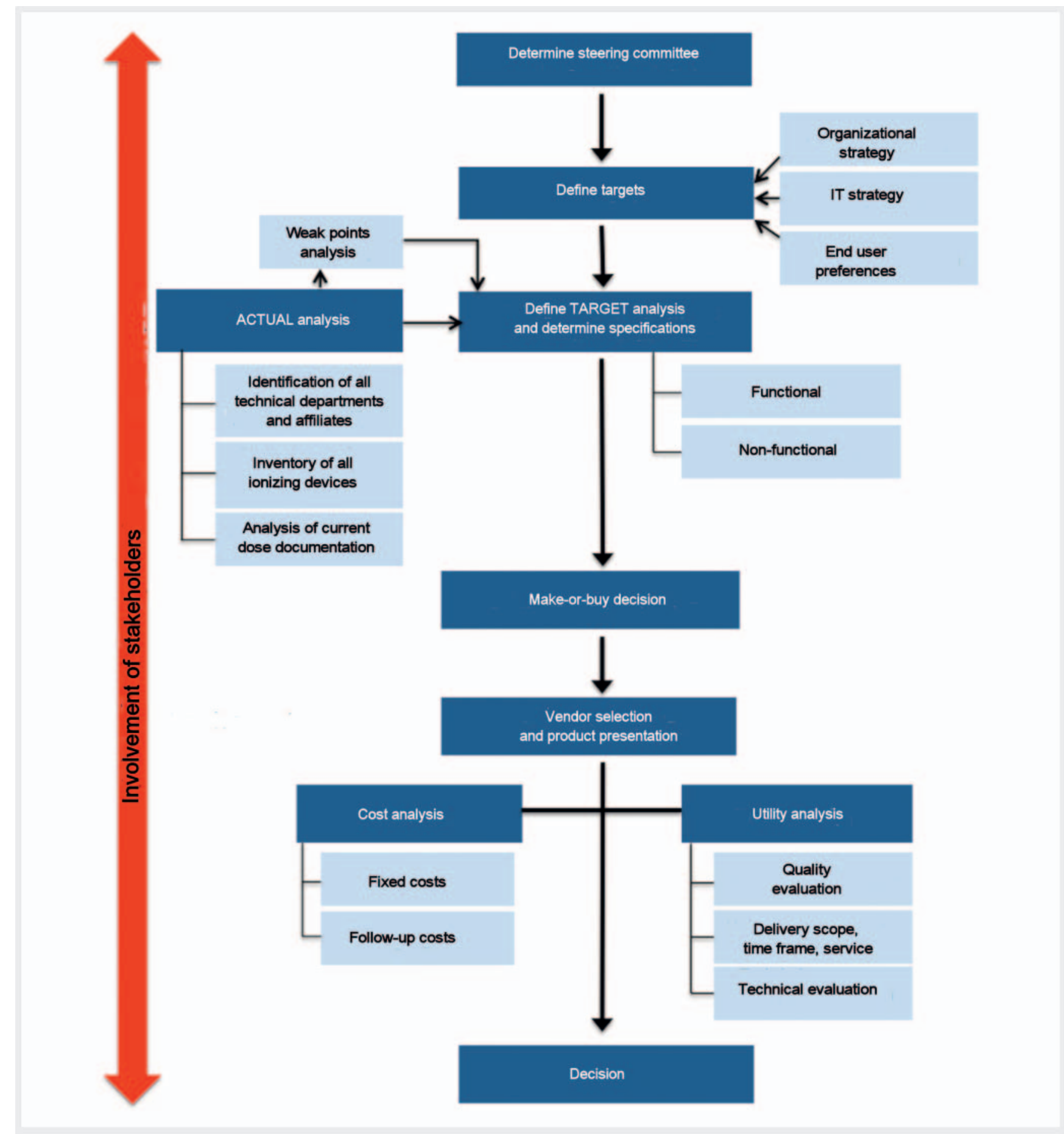

- Fig. 7 Flowchart representing methodology for the acquisition of a dose.

requirements, output option of data and service details. With respect to technical equipment, the legal requirements of the Medicinal Devices Act, Radiation Protection Act and the Radiation Protection Ordinance, data security, technical integration of modalities, authorization concepts, alarm concepts and additional options are evaluated. Additional options should allow assessment of contrast agent consumption, clinical decision support system (CDSS) and clinical audit integration. In radio- logy, a CDSS can aid in the decision regarding the appropriate examination modality for patients with specific clinical issues. These are intended to improve overall planning, process optimization and control. Unlike equipment procurement, the DMS is not required for image generation and reporting, but is used to comply with legal requirements for radiation protection and can be used to optimize processes within the institution. The cost-utility analysis must therefore be carried out particularly 
critically and should be based on the specifically-defined requirements for the software.

A summary of the cost-utility evaluation is shown in > Fig. $\mathbf{6}$, and an overview of the methodological approach for acquiring a dose management system is presented in > Fig. 7 .

\section{Conclusions}

The procurement of a dose management system is a complex project that requires good coordination between various stakeholders (user groups, controlling, IT department and equipment manufacturers). Use of a DMS is unavoidable given the far-reaching legal requirements. The choice is limited by functional requirements, as well as the technical conditions in a hospital with a wide variety of equipment manufacturers as well as cost specifications by the board of directors. Using actual and target, as well as cost-utility analyses, the appropriate product can be sorted out in order to achieve rapid commissioning and the highest possible user acceptance while at the same time optimizing costs.

\section{Conflict of Interest}

The authors declare that they have no conflict of interest.

References

[1] Council of the European Union. Richtlinie 2013/59/EURATOM, Amtsblatt Der Eur. Union. L 13/1 (2014) 1-73. https://www.uni-kiel.de/strahlenschutzseminar/eubss.pdf \%0Ahttp://www.bmub.bund.de/themen/atomenergiestrahlenschutz/strahlenschutz/rechtsvorschriften-technische-regeln/ regelungen-der-eu. [Accessed 08.10.2020].

[2] Bundesministerium der Justiz und für Verbraucherschutz. Gesetz zum Schutz vor der schädlichen Wirkung ionisierender Strahlung (Strahlenschutzgesetz - StrlSchG), StrlSchG. (2017) 1-123. https://www.gesetzeim-internet.de/strlschg/StrlSchG.pdf. [Accessed 05.11.2020].

[3] Walz M, Wucherer M, Loose R. Was bringt die neue Srahlenschutzverordnung? Radiologe 2019; 59: 457-466. doi:10.1007/s00117-019-0508-7

[4] Statista: Statistics and Market data on Software. https://www.statista. com/markets/418/topic/484/software. [Accessed October 12, 2020].

[5] Teich I, Kolbenschlag W, Reiners W. Der richtige Weg zur Softwareauswahl: Lastenheft, Pflichtenheft, Compliance, Erfolgskontrolle; SpringerVerlag; 2008
[6] Dannis, CHAOS Report 2015, Standish Gr. Int. Inc. (2015) 13. https:// www.standishgroup.com/sample_research_files/CHAOSReport2015Final.pdf. [Accessed 28.11.2020].

[7] Stamm G, Rübel HW. Procurement strategy for a dose management system. Radiologe 2021. doi:10.1007/s00117-020-00789-w

[8] Boos A], Meineke A, Bethge OT et al. Dose Monitoring in Radiology Departments: Status Quo and Future Perspectives. Fortschr. Röntgenstr 2016. doi:10.1055/s-0041-109514

[9] National Electrical Manufacturers Association. Digital imaging and communications in medicine, ISO 12052:2017(en), Health informatics Digital imaging and communication in medicine (DICOM) including workflow and data management. https://www.iso.org/obp/ui/\#iso:std: iso:12052:ed-2:v1:en. [Accessed 30.11.2020].

[10] European Society of Radiology. EuroSafe Imaging Stars. http://www.eurosafeimaging.org/stars. [Accessed 01.03.2021].

[11] Bundesamt für Strahlenschutz. Bekanntmachung der aktualisierten diagnostischen Referenzwerte für diagnostische und interventionelle Röntgenuntersuchungen, 22 (2016). [Accessed 01.02.2021]

[12] Damilakis ], Frija G. EUCLID project carries out study to establish clinical DRLs for Europe, in: 28.02.2019, 2019. http://www.eurosafeimaging.org/ wp/wp-content/uploads/2019/08/ECR-Today-2019_Thursday_Feb-28_ EUCLID.pdf. [Accessed December 8, 2020].

[13] Wöhe G, Döring U, Brösel G. Einführung in die allgemeine Betriebswirtschaftslehre: Produktionsplanung. München: Vahlen; 2016: 328-331

[14] American Association of Physicists in Medicine. The Report of AAPM Task Group 204. Size-specific Dose Estimates (SSDE) in Pediatric and Adult Body CT examinations. https://www.aapm.org/pubs/reports/ RPT_204.pdf. [Accessed 30.12.2020].

[15] Couhan PK, Yao hF, Yerima S et al. Software as a Service: Analyzing Security Issues, 2015. arXiv preprint arXiv:1505.01711.

[16] Bork U, Weitz J. Cloud Computing im Gesundheitswesen: Mehr Chancen als Risiken. Dtsch Arztebl 2019; 116: 679-685

[17] Schöffski O, Glaser P, vd Schulenburg J. Gesundheitsökonomische Evaluationen. Berlin: Springer; 2013: 71-110

[18] Schlüchtermann J. Betriebswirtschaft und Management im Krankenhaus: Integration nicht-monetärer Kriterien mithilfe der Nutzwertanalyse. Berlin: Medizinisch Wissenschaftliche Vertragsgesellschaft; 2015: 283-287

[19] Eisenführ F, Weber M, Langer T. Rationales Entscheiden (Entscheiden). Berlin: Springer; 2010

[20] Zangemeister C. Nutzwertanalyse in der Systemtechnik. München, 1976

[21] Vergabeportal. Bewertungskriterien und -matrizen im Vergabeverfahren: Interpolationsmethoden. https://www.reguvis.de/xaver/vergabeportal/ start.xav?start=\%2F\%2F*\%5B\%40attr_id\%3D\%27vergabepor tal_8223873931\%27 and \%40outline_id\%3D\%27vergabeportal_BewertungskriterienMatrizen_8221329931\%27\%5D. [Accessed 01.03.2021]. 